\section{Effects of test line position and age on the magnitude of the Ponzo illusion}

\author{
KATHRYN QUINA and ROBERT H. POLLACK \\ The University of Georgia, Athens, Georgia 30601
}

An earlier study by Quina and Pollack (1971) suggested that the two test lines of the classical Ponzo figure underwent simultaneous distortion in opposite directions. In the present study, test lines were shown individually with comparison lines outside the influence of the wedge to 70 school children in Grades 2-8 and to 10 adults. The apical test line was overestimated by all age groups, and the distal line was consistently underestimated. Dissimilar age trends were found, supporting the concept of the Ponzo illusion as the product of two distinct processes.

A recent study by Quina and Pollack (1971) was designed to test three plausible explanations given for the Ponzo illusion: perspective or misapplication of size constancy, satiation, and assimilation and contrast processes.

Gregory (1963) and Leibowitz et al (1969) have offered the inappropriate use of size constancy as an explanation of the Ponzo illusion. The Ponzo wedge, oriented with its apex at the top, creates the impression of depth. Judgments of the lengths of the lines, then, arebased on their apparent distance from the observer. The apical line, seeming to lie further away, will be judged longer than a line of equal retinal size lying at the open end of the angle. Leibowitz et al (1969) found that addition of perspective cues enhanced the Ponzo illusion. However, a $10 \%$ illusion persisted when such cues were removed, and rotation of the geometric figure 90 and $180 \mathrm{deg}$, thus altering the depth cues, produced no change in magnitude of illusion. Fisher (1968) incorporated a Ponzo figure into various reversible figures, and found equal illusion magnitudes for each apparent depth of the figures (corners projecting towards or away from the observer).

According to Köhler and Wallach (1944), the lines of the Ponzo figure are reduced in size due to satiation of the region lying alongside the inducing contour and containing the ends of the lines. Satiation is greatest not immediately beside the contour, but at some distance out from and parallel to it. Thus, the distal line undergoes greater shrinkage than the apical line because it lies in the latter, more satiated region. Since satiation is immediate, this occurs in the simultaneous illusion as well as in the aftereffect paradigm.

Greene and Lawson (1970) found that, in relation to a comparison figure placed outside the influence of the wedge, a square test figure close to the apex was overestimated, while near the ends of the angle the test figure was underestimated. This supports the assimilation-contrast explanation Fraisse (1971) has given for several illusions.

Assimilation of the ends of lines close to the contour of the wedge to form a virtual triangle should cause an apparent enlargement of those lines, while contrast of the length of the lines further out with the space between the ends of the line and the sides of the wedge should cause an apparent shrinkage of those lines. Although both are operating simultaneously on each line, one force is dominant in each case. This explanation allows for the continued influence of the wedge beyond its ends, which the other theories could not do. Contrast could continue to operate, in decressing strength. though they are not exactly aligned. Pressey (1971) provided evidence in support of an assimilation effect in the Ponzo illusion. He presented the apical triangle with a single line at the distal position and found overestimation of the line at the apex. Thus, the illusion can be obtained without the presence of the entire wedge.

Künnapas (1955) found that the perceived length and width of a line depended on the size of the surrounding frame. $A$ line located in a small square was overestimated in both length and width; in a large square, it was underestimated. Künnapas was framework upon figure rather than contour interactions, but his results are applicable to the present situation.

In the original experiment, Quina and Pollack (1971) presented the test line of the Ponzo figure at each of the six positions shown in Fig. 1, with the comparison line located outside the influence of the wedge. The classical figure was altered in this manner in order to study the nature of the effect produced by the inducing angle on between the line and the wedge, even interested in the effects of visual each line. If the angle creates an impression of depth, as perspective theory holds, there should be overestimation of all lines within the wedge, greatest at the apex and decreasing to zero at its ends. Satiation theory would expect underestimation of all lines, increasing and then decreasing according to the distance paradox (Köhler \& Wallach, 1944, p. 289 ). Assimilation-contrast processes would cause overestimation of lines near the apex and underestimation of lines at the open end. If the illusion is due to a configurational effect, as in Tausch's (1954) contrast explanation, then the present method of breaking up the classical figure should not reveal any systematic distortion.

Two trained Ss viewed the stimuli in tachistoscopic exposures of 250 msec. Both Ss overestimated lines near the apex (Positions 1 and 2). Near-zero scores were obtained for center positions for each. Greatest underestimation was found for Position 5, corresponding with the ends of the angle, although underestimation was still strong at Position 6. Significant linear trends were obtained for both Ss.

Neither perspective nor satiation theories could account for the trends found. The results suggested that the classical Ponzo illusion was actually a product of two basically distinct and independent processes, occurring in opposite directions. Together, they create the effect which most researchers have heretofore considered to be a single distortion effect. Assimilation and contrast were selected as the most likely processes underlying these distortions.

The present study was designed to test the hypothesis that the two lines of the classical Ponzo figure are actually undergoing two separate distortion effects. The two test lines undergoing maximum distortion in each direction in the Quina and Pollack study (Positions 2 and 5, closely corresponding to the lines of

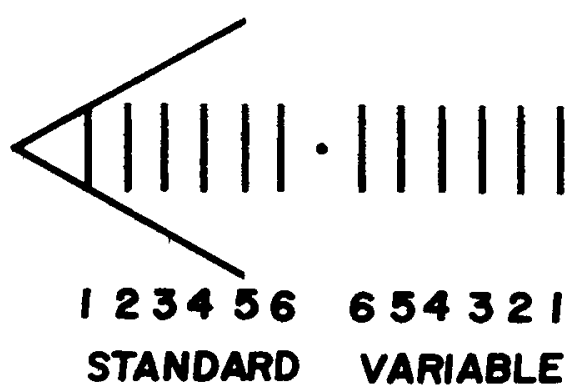

Fig. 1. The Ponzo figure used in Quina \& Pollack (1971) and in the present study. 
Table 1

Illudion Marnitude for Equaln CA Groupa*

\begin{tabular}{|c|c|c|c|c|c|}
\hline \multirow{2}{*}{$\begin{array}{c}\text { Mean } \\
\text { CA (Y ears) }\end{array}$} & \multicolumn{2}{|c|}{ Position 2} & \multicolumn{2}{|c|}{ Poxtion 5} & \multirow{2}{*}{$\frac{\text { Total Illusion }}{\text { Mean }}$} \\
\hline & Mean & SD & Menn & $\mathbf{S D}$ & \\
\hline $\begin{array}{r}7.6 \\
8.3 \\
9.7 \\
11.0 \\
11.7 \\
12.9 \\
13.5 \\
19.1\end{array}$ & $\begin{array}{l}.94 \\
.74 \\
.69 \\
.60 \\
.48 \\
.57 \\
.69 \\
.84\end{array}$ & $\begin{array}{l}.62 \\
.56 \\
.50 \\
.70 \\
.53 \\
.76 \\
.60 \\
.65\end{array}$ & $\begin{array}{r}-.78 \\
-.82 \\
-1.34 \\
-1.54 \\
-1.20 \\
-.88 \\
-.97 \\
-.87\end{array}$ & $\begin{array}{l}.49 \\
.67 \\
.53 \\
.36 \\
.64 \\
.34 \\
.31 \\
.34\end{array}$ & $\begin{array}{l}1.72 \\
1.56 \\
2.08 \\
2.14 \\
1.63 \\
1.55 \\
1.56 \\
1.71\end{array}$ \\
\hline
\end{tabular}

$* N=10$

the classical figure) were selected for study. If two distinct processes are acting on the lines, then two separate developmental trends might be found. The summation of these two trends, then, should give the developmental curves found by other researchers who were concerned only with the total illusion. Comalli (1969), using mean age groups of $6.5,9.5$, and 21 years, found the greatest illusion for the middle group. Leibowitz and Judisch (1967) found an increase in magnitude of illusion up to adolescence, and a smaller, stable illusion thereafter.

Although little evidence is available on the developmental courses of the individual lines of the Ponzo figure, studies of other assimilation-contrast illusions are available. Santostefano (1963) found a decrease with age of the positive Delboeuf illusion and an increase with age of the negative Delboeuf. These have been explained by assimilation and contrast, respectively, by Piaget et al (1942). These findings suggested that overestimation of the apical line of the Ponzo figure, the assimilation effect, would decrease with age. Underestimation of the distal line, the contrast effect, would increase with age.

\section{METHOD}

Subjects

The Ss were 70 school children of lower and lower-middle class backgrounds, 5 males and 5 females from each of Grades 2-8.1 Mean ages were $7.6,8.3,9.7,11.0,11.7,12.9$, and 13.5 years. Each had a visual acuity betterthan $20 / 30$, as tested with the Master Ortho-Rater, and an IQ above 90, as measured by the California Mental Maturity Test. In addition, a group of 10 students attending the University of Georgia, mean age 19.1 , was tested.

\section{Apparatus and Stimuli}

Stimulus figures were drawn in black India ink on $5 \times 7$ white cards. On each card, the inducing angle of $60 \mathrm{deg}$ and the test line, placed at Position 2 or Position 5 , were on one side of a central fixation dot, and the comparison line was equidistant from the dot on the opposite side. The standard line was $11.0-\mathrm{mm}$ long, and the length of the comparison line was varied from 7.5 to $14.5 \mathrm{~mm}$ in $.5-\mathrm{mm}$ steps. All lines were $.5 \mathrm{~mm}$ long. The largest display subtended a visual angle of $3 \mathrm{deg}$. Control stimuli were exactly the same except that the inducing angle was not present, and the comparison line was varied from 10.0 to $12.0 \mathrm{~mm}$ in length.

Stimuli were oriented with the angle on the left, since comparison of leftand right-orientations had revealed no significant differences in Quina and Pollack (1971). They were presented for $250 \mathrm{msec}$ in a three-channel tachistoscope (Scientific Prototype, Model GB). Illumination was constant at $4.8 \mathrm{fc}$, as measured by a Macbeth Illuminometer.

\section{Procedure}

A field containing only a central fixation dot was presented for 3 min before each experimental session, and remained on throughout the session except during stimulus presentations. Ss were instructed to judge, while fixating on the central dot, whether the comparison line was longer or shorter than the standard line. All Ss saw both positions; order was counterbalanced.

A converging method of limits was employed in stimulus presentation, whereby the stimuli appeared with comparison lines in the order of shorter, longer, longer, shorter, converging upon the stimulus with equal lines of $11.0 \mathrm{~mm}$. Each run through the series of stimuli in this order constituted a trial. Trials began with a shorter or longer stimulus in the order abba. Four control trials preceded six experimental trials in each position. Points of subjective equality (PSEs), defined as $.25 \mathrm{~mm}$ below the first change in response maintained for three consecutive values in ascending or descending order, were calculated for each trial. Control PSEs were subtracted from experimental PSEs to find the magnitude of illusion.
RESULTS

The apical line, Position 2, was overestimated by all age groups, and the line corresponding with the ends of the angle, Position 5, was consistently underestimated (Table 1). Three stepwise multiple regression analyses were performed on the data. ${ }^{2}$ This test was selected over the regular analysis of variance in order to preserve the continuity of the chronological age (CA) and mental age (MA) variables. The multiple regression procedure offered the further advantage of taking into account the unequal distances between the age groups.

The stepwise procedure takes each variable in order of importance, and tests the significance of that variable over and above the variables already entered. In addition, the old variables are reanalyzed for importance in light of the entered variable (Draper \& Smith, 1966, pp. 171-172; Darlington, 1968). In each analysis, the variables were entered in the order: main effects (linear), squared main effects (quadratic), and interactions. The $F$ values shown, therefore, must be interpreted differently for the three types of variables: (1) Main effects-significance indicates that the variable is significant over and above linear information contained in all the other main effects. (2) Squared main effects-significance indicates that the best prediction equation includes a quadratic component; this component is significant over and above information contained in other quadratic components and all main effects. (3) Interactions-significance of interactions is over and above the information contained in the main effects, the quadratic components, and the other interactions.

In the first analysis, the main variables were CA, order, sex, and test line position. In addition, the quadratic prediction equation for $\mathrm{CA}$ was tested separately for each of the test line positions. Major interactions were then entered and tested.

Test line position was highly significant $[\mathbf{F}(4,149)=373.48$, p $<.001]$, reflecting the opposing directions of the two distortions. Main effects of sex and CA were not significant. Significant order $[F(4,149)$ $=5.88, p<.001]$ and Order by Position $[F(10,149)=4.23, p<.001]$ effects were found. The quadratic CA component was significant for both test line positions [for Position 2, $F(6,149)=10.23, p<.001$; for Position 5, $F(6,149)=10.96$, $p<.001]$. When this component was entered, the reevaluated $F$ value for the linear CA variable also increased to significance $[F(6,149)=10.43$, $p<.001]$, indicating that the 
appropriate prediction equation for the age trends included both linear and quadratic components; that is, a positively skewed curve. No other interactions were significant. $74 \%$ of the total variance was accounted for in these analyses.

In order to compare the relative importance of $\mathrm{CA}$ and $\mathrm{MA}$ in determining the trends obtained, both linearly and quadratically, a second analysis was performed. MA values were not available for the 10 college students, so they were not included in the analysis. Again, significance was found for the test line position $[F(4,128)=311.52, p<.001]$ and order $[F(4,128)=5.39, p<.001]$. Linear information in $\mathrm{CA}$ and $\mathrm{MA}$ variables was not significant. The quadratic CA predictor was found to be significant over and above the effects of both linear and quadratic MA predictors for each test line position [for Position 2, $F(8,128)=$ 4.34, p <.001; for Position 5, $F(8,128)=4.42, p<.001]$. Again, no significant sex differences were found. The proportion of total variance accounted for was .73 .

The scores for Position 5 were inverted for a third analysis, resulting in the positive curves shown in Fig. 2. By thus erasing the directional differences of the two distortions, their absolute magnitudes could be compared. All Ss were included in this analysis; the variables were the same as those in the first analysis.

The main effect of the two test line positions was still large and significant $[F(4,149)=18.06, p<.001]$; again, the order effect was found $[F(4,149)$ $=4.74, p<.01]$. Main effects of $\mathrm{CA}$ (linear) and sex were not significant. The only significant interaction was that between $\mathrm{CA}$ and test line position $[F(10,149)=9.57, p<.001]$. When that interaction was entered, $F$ values for both quadratic CA components were increased from nonsignificance to a significant level [for Position 2, $F(7,149)=4.38, \quad p<.001 ;$ for Position 5, $F(7,149)=6.80$, $p<.001]$. This was due to the masking of the quadratic age trend by the interaction between $C A$ and test line position. The proportion of the total variance accounted for in this analysis was 24 .

Finally, the absolute magnitudes of the two illusions were summed. This is shown in Fig. 2. The sum of the two effects increased to a peak at 11.0 years and declined thereafter.

\section{DISCUSSION}

The consistent overestimation of the test line at Position 2, and its underestimation at Position 5, lend additional support to the assimilation-contrast explanation given

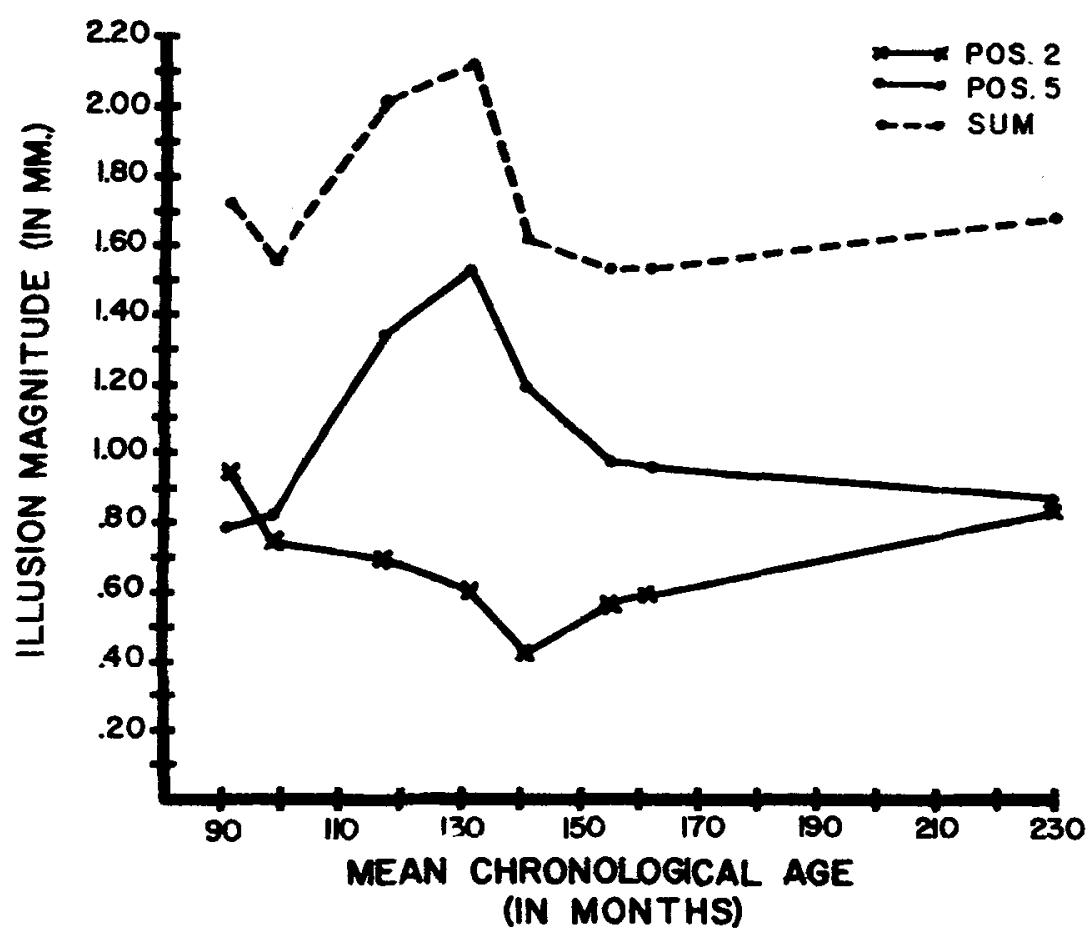

Fig. 2. Absolute magnitude of illusion as a function of CA. Equal-n age groups were formed for use in the figure. "Sum" indicates total illusion.

in Quina and Pollack (1971). Again, perspective and satiation theories cannot account for these findings.

The significant interaction between $C A$ and test line position found when the absolute magnitudes of the two distortions were compared gives strong support for the hypothesis that the two positions are actually influenced by two distinct processes. The finding that CA was important over and above $\mathrm{MA}$ in producing the developmental trends suggests that both the assimilation-like overestimation of the apical line and the simultaneous contrast-like underestimation of the line at the ends of the wedge should be considered as being lower-level developmental processes. No explanation can be offered for the significant order effects found; however, order was completely counterbalanced in the design.

The expected linear trends were not found. Rather, quadratic trends were found in each case. The increase and subsequent decline in magnitude of the contrast effect (Position 5) appears to be an exemplar of the Type III illusion discussed by Piaget (1967). At first, illusion magnitude increases with age, as the child's framework of perceptual relations broadens. As this effect decreases in importance, the centration effect (causing overestimation of the line centered upon) becomes more important in determining the illusion magnitude. Around the ages of 9-11, the centration effect becomes dominant, and the illusion effect then follows the Type I trend of decrease in magnitude with age due to increasing ability to decentrate.

According to Pollack (1969), Type I illusions are based on perceptual processes alone and decrease with age as a function of physiological changes in the receptor system (increasing lenticular density and retinal pigmentation). This theory has been supported in studies correlating density of fundus pigmentation with susceptibility to the Mueller-Lyer illusion (e.g., Ebert \& Pollack, 1972). Younger children, however, may be drawn to the apex of the angle and thus may not be as susceptible to the Type I contrast effect (even though they have been instructed to fixate on the dot). After the peak age of 11 years, attention may have broadened sufficiently to include both the apex and the line further out, and the regular Type I pattern appears. According to Vurpillot, there is a possibility that all Type I illusions would exhibit Type III curves if one could test very young children (Jenkin \& Pollack, 1966, p. 163). The importance of $\mathrm{CA}$ in the age trend found in the present study suggests the latter interpretation.

The findings for Pasition 2, the apical position, are not so easily explained. Up to 11.7 years, the trend looks like a Type I trend, agreeing with the suggestion that it is a 
lower-level developmental process. There is no readily available theoretical statement to account for the rise in the magnitude of illusion beyond this age. Since this appears to contradict the theories of both Pollack and Piaget, future parametric work on the assimilation effect is planned.

The summation of the two curves produced a total effect which peaked at 11 years. This curve bears a marked resemblance to the mean illusions reported by Comalli (1969) for his Ss. Since he used only ages corresponding to the first, third, and last groups in the present study, we can only compare these; the peak he found at 9-10 years is again found here. The results are similar as well to thase of Leibowitz and Judisch (1967). The differences in procedure, particularly the restriction of head and eye movements, the small size of the figures, and the nature of the stimulus configuration in the present study, may account for the 2-year difference in peak age.

The separate age trends found for the two test line positions support the hypothesis that there are actually two simultaneous and opposing processes occurring within the classical Ponzo figure. The distortion effects seem best explained by assimilation and contrast processes. Furthermore, the similarity of the developmental trend of the total illusion to the data of Comalli favors the position that what previous researchers have been looking at is a summation of two distinct effects.

\section{REFERENCES}

COMALLI, P. Perceptual changes to visual illusions in childhood, adulthood, and old age. Paper presented at Meeting of the Society for Research in Child Development, Santa Monica, California, March 1969.

DARLINGTON, R. B. Multiple regression in psychological research and practice. Psychological Bulletin, 1968, 69, 161-182.

DRAPER, N. R, \& SMITH H. Applied regression analysis. New Yodk: Wiley. 1966.

EBERT, P. C., \& POLLACK, R. H Magnitude of the Mueller-L yer illusion as a function of lightness contrast, viewing time, and fundus pigmentation. Psychonomic Science, 1972, 26, 347-348. FISHER, G. H. The framewarks for perceptual localization. Newcastle upon Tyne, England: University of Newcastle upon Tyne Press, 1968.

FRAISSE, P. L'integration temporelle des lements des illusions optico-geometriques et l'inversion de I'ill usion de Muller-Lyer. L'Année Psycholozique, 1971, 71, 53-72.

GREENE, R. T. \& LAWSON, R. B. Ponzo wedge effects upon stereoscopic size and distance. Paper presented at the meeting of the Eastern Psychological Association. Atlantic City, New Jersey, April 1970.

GREGORY, R. L. Distortion of visual space as inappropdate constancy scaling Nature, 1963, 199, 678-680.

JENKIN, N., \& POLLACK, R, H. Perceptual development: Its relation to theories of intelligence and copnition. Proceedines of a conference sponsored by Institute for for child Health and Human Development. Institute for Juvenile Research, Chicago, 1966.

KOHLER W \& WALIACH, $H$ Figural aftereffects: An investigation of visual processes. Proceedings of the American Philosophical Society, 1944, 88, 269-357.

KUUNNAPAS, T. M. Infiuence of frame size on apparent length of a line. Journal of Experimental Psychology, 1955, 50, $168-170$

LEIBOWITZ, H., \& JUDISCH, J. The relation between age and the magnitude of the Ponzo illusion. American Journal of Psy chology, 1967, 80, 105-109.

LEI B OWITZ, H., BRISLIN, R.,
PERLMUTTER, L., \& HENNESSY, $R$. The Ponzo perspective illusion as a manifestation of space perception. Science, 1969, 166, 1174-1176.

PIAGET, J., LAMBERCIER, M., BOESCH, E., \& von ALBE RTINI, B. Recherches sur le developpement des perceptions: I Introduction à l'étude des perceptions chex l'enfant et analyse d'une illusion relative à la perception visuelle de cexcles concentriques (Delboeuf). Archives de Psychologie, Geneve, 1942, 29, 1-107.

PI AGET, J. Problems of genetic psychology. In D. Elkind (Ed.), Six psychological studies. New York: Random House, 1967.

POLLACK, R. H. Some implications of ontogenetic changes in perception. In $D$. Elkind and $J$. Flavell (Eds.), Eseays in cognitive development: studies in honor of Jean Plaget. Oxford: Oxford University Press, 1969. Pp. 365-407.

PRESSEY, A. W. An extension of assimilation theory to lllusions of size, area, and direction. Perception Psychophysies, 1971, 9, 172-176.

QUINA, K. \& POLLACK, R. H. Parametric investigation on the Ponzo illusion under conditions of tachistoscopic exposure. Proceedings, 79th Annual Convention. American Psychological Association. $1971,77-78$.

SANTOSTEFANO, S. A developmental study of the Delboeuf illusion. Perceptual \& Motor Skills, 1963, 17, 23-29.

TAUSCH, R. Optische Tiluschungen als artifizielle Effekte der Gestaltungsprozesse von Grössen- und Formenkonstanz in der natiudichen Ra umwahrnehmung. Psychologische Forschung, 1954, 24, 299-348.

NOTE

1. Special acknowledgment goes to $\mathrm{Dr}$ william Love, who suggested the statistical analyses and programmed them.

2. The authors wish to express their gratitude to Mr. Lloyd Cash, Principal, and the staff of Lanier Elementary. School, Gainesville, Georgia, for providing $S$ s for this experiment.

(Accepted for publication June 9, 1972.) 